Document downloaded from:

http://hdl.handle.net/10251/102695

This paper must be cited as:

Martínez Novo, R.; Lizcano-Fernández, E.; Herrera Racionero, P.; Miret Pastor, LG. (2017). Aquaculture stakeholders role in fisheries co-management. Marine Policy. 76:130-135. doi:10.1016/j.marpol.2016.11.015

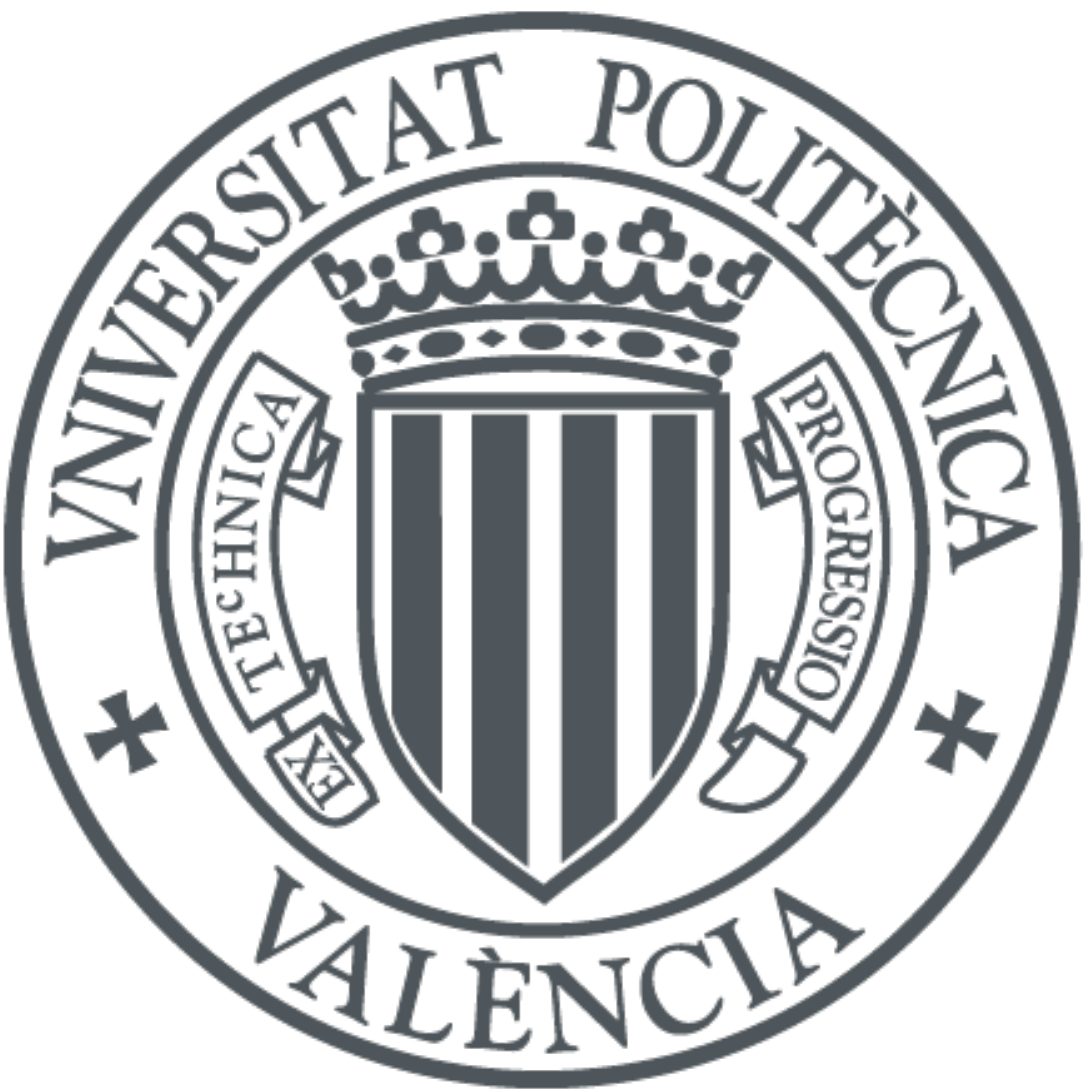

The final publication is available at

http://doi.org/10.1016/j.marpol.2016.11.015

Copyright Elsevier

Additional Information 


\title{
Aquaculture stakeholders role in fisheries co-management
}

Rodrigo Martínez-Novo

Emmánuel Lizcano. UNED

Paloma Herrera-Racionero. IGIC. Universitat Politècnica de València.

Lluís Miret-Pastor. IGIC. Universitat Politècnica de València.

\begin{abstract}
Industrial aquacultur has become one of the main protagonists both on the coasts and in international policy aimed at regulating matters concerning the sea. This new role is reflected in the recently adopted Common Fisheries Policy of the European Union, where the need to promote the sector and the involvement with other local actors, specifically artisanal fishermen, is highlighted. However, the official promotion of this activity could be overvaluing its benefits while, at the same time, undervaluing the new barriers that it is introducing in fisheries co-management. Centered in Valencian Community (Spain) and through a qualitative methodology, this paper examines the views and positions of stakeholders directly involved in aquaculture activity (biologists, aquaculture businessmen and policy managers) on the possibilities of joint participation. It is concluded that eroding the detected mistrust among stakeholders through "hybrid forms of participation" would be a necessary prerequisite to setting up a common framework for involvement leading to an effective co-management.
\end{abstract}

Keywords: Aquaculture; co-management; traditional fisheries; Common Fisheries Policy; aquaculture stakeholders role. 


\section{Aquaculture stakeholders role in fisheries co-management}

\section{Introduction}

The European Union (EU), the Food and Agriculture Organization of the United Nations (FAO) and other international institutions are stressing the need to boost both marine aquaculture and local fishery as two important axes for attaining environmental and social sustainability. Nevertheless, the relationship between these two activities has often been controversial so both activities compete for space and for resources in the marine and coastal areas $[1,2,3,4]$ and, at the same time, they are competing for customers in the market [5].

This dynamic contrasts with policies and recommendations regarding coastal governance and management. Within these, there is an explicit recognition of the value of local stakeholders and their knowledge in contributing to the resolution of many coastal problems. Institutions such as the FAO or the EU have recognised the importance of small-scale fishery and aquaculture for poverty alleviation and prevention, pointing out its contribution for generating income, employment and obtaining food. The noninclusion of local stakeholders in national and regional policies can block this contribution [6,7]. The new Common Fisheries Policy (CFP) has introduced very important changes in coastal regulation and governance. In previous reports, the European Parliament admits that "the centralised management frequently produces guidelines that are divorced from reality, poorly understood by the sector (which is not involved in discussing or developing them), and difficult to implement, producing results that are often the opposite of those intended [8]. Therefore, it highlights "the importance of ensuring that all relevant interested parties are involved in the development of policies 
concerning small-scale coastal fishing and artisanal fishing" [8]. It is focused not only on strengthening the need to carry out a 'participatory strategy of local development' in which communities such as fishermen are included, but also on trying to boost this innovative aquaculture, whose legislation was becoming increasingly contradictory in relation to comprehensive management and to involvement itself. This idea appears on paragraph 56 of the European Maritime and Fisheries Fund, 2014-2020, which arises from this policy: "In the fishery and aquaculture sector, community-led local development should encourage innovative approaches to create growth and jobs, in particular by adding value to fishery products and diversifying the local economy towards new economic activities, including those offered by 'blue growth' and the broader maritime sectors" [9].

The matter, of course, is not simple: seas and coasts are characterized by multiple jurisdictions, multiple habitats and scales, and - above all - by many conflicting and/or competing interests. But also, many of these co-management models - understood in a general way as "a resource management partnership in which local users and other stakeholders share power and responsibility with government agencies" [10] - do not explicitly consider the role of a more diverse set of stakeholders, or what roles different stakeholder types are best positioned to perform $[11,12,13]$.

Despite this, it is a fact that many of the experiences of collaboration between fishermen and aquaculture farmers have resulted in failure. Most of the literature that has analysed these initiatives has been based on the point of view that fishermen have on aquaculture and some authors even suggest that it is easier to turn people with farming experience into aquaculturists than to do so with people who are highly focused on fishing [14]. This difficulty of involving fishermen in aquaculture is not only due to economic reasons, but also -and in particular-to cultural ones, related to prestige or to personal satisfaction 
$[15,16]$. Besides the underlying perceptions, attitudes and stereotypes of fishermen by other stakeholders is important inunderstanding the poor institutional interaction and cooperation $[17.18,19,20]$. In any case, it seems to be believed that the failure is more related to fishermen who resist collaborating than to other stakeholders, assuming, perhaps unconsciously, that legislation does promote co-management and that it is accepted by stakeholders involved in aquaculture.

Co-management literature has focused on barriers arising from characteristics and perceptions that guide the actions of fishermen $[21,22,23]$ but little on the perceptions of new actors linked with innovative aquaculture, especially those that are supposed to be related, theoretically, as a triple helix to push the innovation: university, industry and governmental agencies [24,20]. This paper focuses on them. Based on one of the most representative regions in Europe of both activities, the Valencian Community (VC), the next section justifies the study area as a paradigmatic context to this study. The third section shows the research method, which is based on the qualitative analysis of interviews with outstanding actors in the aquaculture world. The fourth section focuses on the perception that stakeholders directly involved in aquaculture activity (policy managers, biologists and businessmen) have about the possibilities and forms of joint involvement. Finally, the main conclusions are presented in the last section.

\section{Study area}

Spain is a country with a great fishing tradition. Its coastline covers $5,000 \mathrm{~km}$, there is a habitual presence along the entire continental shelf of fishermen who, along with aquaculture, today play a very significant socio-economic role.

Regarding aquaculture, Spain is the EU country with the highest volume of production: 240 tonnes in 2013 , out of which $94.07 \%$ comes from cultivating marine species and the 
rest from continental aquaculture. However, when evaluating the value of the production, Spain is in fourth place, with 457,3 million Euros, behind the United Kingdom, France and Greece [6]. Within Spain, the Mediterranean region of Valencia is, along with Murcia, the region that produces the greatest amount of fish: $21.6 \%$ of national production [26].

Since the nineties to the present, the value of the aquaculture production in the VC has been on an upward trend. In contrast, the sector's workforce has declined from 581 employees in 2008 to 424 in 2013, a trend that is repeated throughout the state [26] .This period coincides with an economic context of crisis in which the sector is reorganized through changes in ownership, corporate takeovers and the concentration of the marine facilities of the producers in the region.

To sum up, the production increase shown by aquaculture activity in the $\mathrm{VC}$-which Valencia's government expects to double by 2030 [25] fuelled by the new CFP-contrasts with an inverse dynamic regarding employment. This is undoubtedly related to a process of business concentration that has led, since the beginning of the crisis, to only 13 marine fish aquaculture companies remaining, which are distributed among an even smaller number of business groups. Most of these are multinationals dedicated to various activities (gaming, construction, service stations...) and sometimes linked to venturecapital business groups. Thus, aquaculture in the region has gone from average production units to big concentrations of more efficient production, demanding a higher level of technology and a less intensive use of labour [26,27].

Aquaculture shares space in the harbours of the $\mathrm{VC}$ with local fishing, which represents the majority of fishing in the area. The number of boats and the value of catches follow a decreasing trend, which contrasts with aquaculture's productive growth. The reasons for these decreases are not only related to the scarcity of marine organisms, as a result of pollution and over-exploitation, but also to subsidies for scrapping vessels, to the oil 
crisis, and to other factors, such as difficulty in competing within an internationalized fish market[28,29].

This downward trend in the number of vessels and the value of catches is repeated for the fishing workforce in general, but it is noteworthy that traditional fishing has kept (and even increased) the number of workers since the crisis began [25]. Fishermen themselves confirm the feeling that traditional fishing has behaved as an employment shelter. For years, many fishermen left their profession to work in other less arduous and better-paid jobs (especially in construction); however, the crisis forced many of these workers to go back to their former profession.

In short, while in aquaculture there is a tendency towards higher production, but a lower demand for jobs, in traditional fishing the situation is the opposite: there is a declining trend in value of catches and vessels although, comparatively, there is significant stability regarding employment ${ }^{1}$.

\section{Materials and Methods}

Collaboration among differ actors is conditioned, among other factors, by their level of trust in sharing knowledge. Knowledge is related to different perception and practices and the lack of trust can induce fear, which become a significant barrier for these actors to plan activities in the long term and to guarantee proportional distribution of benefits [30]. The rationales of government interventions are addressed in order to overcome those barriers. The provision of a regulatory framework establishes different approaches to drive the activities of the stakeholders. On the one hand, government can help to break rigidities between them (values and perceptions shaping behavioral and organizational

\footnotetext{
${ }^{1}$ Both activities, in terms of employment, are not very significant but, hand-in-hand with tourism, they are the two main activities which shape the Valencian coast.
} 
barriers), as well as mitigate anticipatory myopia in order to reveal potential opportunities of innovations, specially when the agents should operate in a complex system in term of political levels and multiple overlapping policy settings [31,32]. On the other hand, policies may favor "opening up" or "closing down" the processes of collaboration intruding actors with different perspectives and types of knowledge $[33,34]$. Therefore, it would be necessary to detect which factors are increasing mistrust of stakeholders and thus generating the closure of its feasibility.

This research analyses qualitatively the implicit assumptions present in the discourses of aquaculture protagonists. In order to do so, we performed 17 semi-structured interviews with scientists (marine biologists), managers with direct responsibility for aquaculture activities, and businessmen ${ }^{2}$. Interviewees were asked about their practices, following a brief survey but prioritizing their own rhythm, so that they could freely express their own symbolic universe -with minimal guidance-. They were audio-recorded, transcribed and dissected into "meaningful statements" using Maxqda. A qualitative analysis was made, underpinned by a critical-discourse approach $[35,36]$. The issue of joint involvement was not explicitly raised in the interviews in order not to force the interviewees' answers; thus, the chosen extracts came up spontaneously during conversations. These statements reveal the positions of the people interviewed. They are representative because of the reiteration of opinions condensed in the analysed extracts and not because they provide a statistically significant sample. From this point of view, the number of interviews required depends on the degree of conceptual saturation: more interviews do not report new outstanding information.

\footnotetext{
${ }^{2}$ Indeed, there are differences between these three groups butthey strive to save them when referring to other stakeholder, like fishermen.
} 
On the collected discourses we have performed a sociological analysis, seeking to detect the implicit meanings [37] or the a priori [38] that drive their actions. The poetic and hermeneutic perspective that predominates in our analysis does not so much address the descriptive and expressive functions of language, in terms of their productive and dialogical functions. The consideration of language as a channel of latent collective voices allows us to examine the discourses as verbal creation processes produced within broader socio-historic processes.

\section{Results and discussion}

The distrust of fishermen towards other stakeholders has been studied widely $[23,19.11]$. We ourselves have analysed it in depth in a port of the Valencian coast [21]. For fishermen, coastal actors are divided into two basic groups: "us" and "them", "them" referring to these three agents. They distrust the ignorance attributed to the "white-collar people" ("The politicians come and they don't have a clue ... they make the law and do not know the issue"), biologists ("We know the sea. Not what the biologists say) and to the power of large companies ("How can a single guy or a fishermen's guild fight against Carrefour?") [21]. However, there is little research on the willingness of stakeholders in coastal aquaculture to collaborate, both among themselves and with local fishermen.

Interviews with scientists (marine biologists), businessmen and policy managers involved directly in aquaculture allow us to observe from which stakeholders they demand collaboration, the terms on which they put forward this demand and, finally, the role they attribute to fishermen in that scenario of governance demands.

Worthy of note is the solidarity between the three types of actors involved in the triple helix of aquaculture: 
"What is talked always about. The relationship between industry, science and administration has to be tightened. The relationship has to be tightened. Round table and that's it. I mean, the relationship is not essential, but it is the ideal framework. But the problem is that, to work properly, they have to work in unison" $(\mathrm{S}-5){ }^{3}$

The "industry, science and administration" (businessmen, scientists and managers) constitutes the "ideal" framework within which the relationship among its members "has to be tightened". Fishermen are not even mentioned. And this seems to be usual, as it is "what is always talked about" within conversations about this issue. The three fundamental instances precipitate around an innovation helix, which dilutes the important differences that should continue to maintain its actors.

It is within this framework made up of those three players, where reciprocal demands arise and where the difficulties of achieving "working in unison" - as we have been repeatedly told - are pointed out (S-5). However, achieving it would be ideal, it is a "luxury" (B-10), therefore "this is what has to be encouraged" (M-11).

Our interviewees describe the above-mentioned difficulties as follows, while at the same time they allow us to confirm how they conceive the social status of the actors involved in aquaculture.

"Any scientist who is valued because of the quantity of his publications should be valued because of their applicability, their utility. It is wrongly set up, because they are used to getting subsidies and researchers do not want to solve problems but publish. They do not reach companies" (B-17).

\footnotetext{
${ }^{3}$ We have identified the informants with S (Scientist), M (Policy Manager), B (Businessman).
} 
"The general Spanish company is not very given...companies and research are on bad terms with each other. [...] The businessman goes to his company and one grows lettuce and the other one fishes, and what he wants are solutions and they are not so easy to get. There has to be a source, and the source is research, and research has to be turned to, not only when somebody has an emergency" (S-3).

As we see, on the one hand businessmen point out the need of not isolating knowledge within the academic field. From this point of view, scientists are considered to be used to receiving subsidies and, as a result of this, they tend to be stuck on the objective of publishing. They do not solve problems, understood as company problems: "They do not reach companies". On the other hand, this biologist's criticism is addressed to (Spanish) companies because of their lack of interest in research. He is demanding from them that they "have to turn to research". This attitude of making oneself the fixed point to which all the others have to turn is common to all players. So, for the following manager:

"The same instrument, in the hands of some managers or in those of others, means that it works or it does not work. And we know it. Therefore, this also requires, firstly an element of training, in the broad sense, of managers. Secondly, it is not about financial resources, but about the culture of financial markets to support innovation. Because the assessment of risk projects is different, and there we have a deficit in relation to other countries such as the USA, which is clearly significant" (M-13).

Besides the centrality and enhancement of his specific role, this informant adds the proposal of a common meeting framework: "the culture of financial markets to support innovation". The interests of scientists (developers of "innovation") and the managers 
themselves (responsible for "project assessment") could converge in that culture. Once again, fishermen are not even mentioned, and they are implicitly excluded, as their culture is completely unconnected, if not incompatible, with the so-called "culture of financial markets". The following interviewee, also a manager, suggests a similar meeting framework, although less ambitious: the business world and the business mind:

"The companies that I know have been reconverted to aquaculture, they are companies that had never had any linking with the sea or with extracting fishing, they have seen a business opportunity and they have set it up. Scientists have to collaborate with this and this is what has to be encouraged" $(\mathrm{M}-11)$.

As the manager's role is to combine existing interests (particularly those from the industry and scientific innovation), it seems logical that he looks for scenarios where both fields can meet. But where the scientist was demanding the move from the business field towards the science field, managers seem to encourage movement in the other direction: increasing scientists' awareness of business needs and “financial culture".

If a businessman cultivates fish in the same way that he "grows lettuces" and if, without having had "any link to the sea or to extracting fishing", he sees in aquaculture only another possible "business opportunity", it is not surprising that players unconnected to this trading and financial mind or those whose pecuniary interest is rooted to the local socio-cultural context are excluded. In particular, those players concerned about environmental sustainability (ecologists) or fishermen, many of whom are also employers (boat owners), are excluded, a lot of whom were recognized actors by governance policies. The universe of fishermen is passed over in these considerations, and when it does explicitly appear in the interviews it is not 
to demand something from it, as happened in the previous statements regarding business or science. The field of traditional fishing is not perceived as the bearer of something valuable that could be interesting to other agents, but as an obstacle in the way. An obstacle to confront ("we are at war"), completely modify ("retrain"), or at best, erode ("make it evolve"), moving them out of their own place to take them to that of industry (the skipper as "company boss") or to that of science ("they start to see things").

In fact, fishermen are perceived as people who are closed, both to the presence of other and to changes and innovations:

"Fishermen is a closed guild so ... quite closed somehow, they have to share the port ... everything seems to bother them, right? Fishermen also understand that sea has always belonged to them and now they have to share it with producers" (M-12).

"We face again the psychosocial problem that means, one [the fisherman] has done what he has done throughout all his life. Changing, innovating is difficult, he conceives it as something that does not belong to him, beyond painting his boat, getting more power for it, or staff security, just getting some kind of subsidy for it, to make a better month" (S-6).

Significantly what was once the main objective for the manager - spreading a mentality that gives priority to economic benefits - is perceived as a defect and a sign of selfishness when the fisherman is the one who seeks it. This assumption of a selfish fisherman is usually invoked to legitimize "top-down" policy and it is similar to the one at the origin of the theory of the tragedy of the commons [39]. So 
it is not uncommon that the relationship with fishermen is formulated in terms of war:

"It is more difficult that they would work for them [for aquaculture farmers]. That is why peace has not been reached yet and we are still at war. Because, many times, those who lead the path - as in Israel and Palestine - must be four blockheads who just can’t get it right" (S-3).

But this bloody-mindedness can be broken, by modifying their habits and values and redirecting them towards those of industry:

"That was the idea at the beginning, which means, many boat skippers have turned to aquaculture. It was maybe more difficult or inappropriate for sailors, because they are more used to a series of contacts...let's say changes and so on, casting and gathering the fishing nets and so on. I do know that some of them did [turn to aquaculture], but above all those who had the ability to get a licence, as coastal fishing skipper, or deepsea skipper, or motor skipper. Those have really come across, because a boat is a boat, and as I tie it in the harbour, I tie it to a cage" (S-1).

Or by altering their psychology until they are able to include science's habits and values, even if this is conceived as something very difficult and possible only in a few cases:

"It is true that we are starting to see some things. They [fishermen] are noticing that scientific information can be useful to them. You can suddenly find an ally, but really in very few cases, not in general. It is a psychology with a very particular environment that will have to evolve, but it is difficult" (S-6). 
However, in some cases, the fishermen's resistance to leave their activity is understood, and stimuli are suggested that could attract them towards an alignment with the other players. Nonetheless, these stimuli do not include any recognition of their knowledge or experience, and they are focused on encouraging their expectation of economic benefits:

"I am convinced that in fishery - it is part of their peculiarities - it is normal that they are pissed off. Fuck! It is normal that they are pissed off, because they see only harm. Their spaces are taken away, they are not allowed to go where they want to, their market is taken away, give them fucking something! As soon as they get involved in aquaculture and get benefits, the problem is over" (M-13).

"Then, of course, we are going to bring together the fields of fishery and aquaculture. And instead of suggesting ways like those we are talking about, we will increasingly get them involved with economic benefits and so on. What I do... I set up the farm. Come to work on the farm! And what do I do with my boat? I do not find the collaboration proposal feasible. They can do it, but this is too radical. The fishing world is very independent, the skipper is the king, he does not depend on anybody. Each boat skipper is a company boss" (S-2).

Although the fact of encouraging the fisherman with the perspective of greater benefits could be an incentive to attract him towards a possible participation, it will be just a passive participation, and anyway, it is considered very unlikely to happen. From these premises it seems really difficult to reach a co-management that is effective and equally satisfactory to all the parties involved. 
Although the fact of encouraging the fisherman with the perspective of greater benefits could be an incentive to attract him towards a possible participation, it will be just a passive participation, and anyway, it is considered very unlikely to happen. This asymmetry in the respective claims and the assessment of the different agents clearly reflects the very different positions of power held by some agents over others. From these premises it seems really difficult to reach a co-management that is effective and equally satisfactory to all the parties involved

\section{Conclusions}

In Europe, fishery regulations seem to have revived the interest which arose in 2002 for the collaboration of all the stakeholders involved. This new role is well reflected in the recently adopted Common Fisheries Policy, where the need to promote local development with techno-scientific innovation in aquaculture and with the involvement of other local actors, as traditional fisherman, is highlighted.

However, although the collaboration between them is justified by social and environmental sustainability, this objective may be jeopardized if their huge differences are not recognised.

In this sense, the sustainability of the marine environment and the participation of other agents may be compromised before the protagonist or dominant role played by the discourse of aquaculture.

The discourse of the reporters -whether scientists, businessmen or policy managers- show a mutual solidarity that tends to overcome the barriers they detect between themselves. Although each of these positions often tries to bring the other two to their own 
perspective, they never question the existence or the need for a common collaborative space to work together.

However, the presence of other actors is either ignored, either seen as an obstacle to the progress of aquaculture. Thus, although traditional fishermen have a situated knowledge based on long experience, they are only perceived as showing an alleged passivity or resistance to change, which is even described in military terms: "We are still at war." The only possibility for collaboration they would admit would necessarily imply the fishermen's abandonment of their own customs and values, in order to embrace the ones of industry, science and market.

Eroding the distrust among stakeholders and their knowledge, as detected in this and other studies, would therefore be a prerequisite to establish a common framework for effective collaboration. In order to do so, the willingness of institutions to build channels of dialogue -materialized beyond the paper stage- is essential. Perhaps boosting "hybrid participatory processes" involving actors with heterogeneous nature and different skills and status, [40], where decisions are made through dialogue between actors with different types of knowledge and practises (traditional and scientific for example) would be a good choice. These processes, although not without problems, can improve coastal governance by incorporating perspectives that usually go unnoticed to those commonly considered experts in innovation.

\section{Founding}

The authors would like to thank the Spanish Economy and Competitiveness Ministry for its support through the Research Project (CSO2013-41972-P).

\section{References}


[1] Mikkelsen, E. Aquaculture-fisheries interactions Mar. Resour. Econ. 2007; 22 (3): 287-303.

[2] Wiber, M. G., Young S. and Wilson, L. Impact of aquaculture on commercial fisheries: fishermen's local ecological knowledge. Hum. Ecol. 2012; 40 (1): 29-40.

[3] Natale, F., Hofherr, J., Fiore, G., and Virtanen, J. Interactions between aquaculture and fisheries. Mar. Policy. 2013; 38: 205-213.

[4] Ramos et al. Perceived impact of offshore aquaculture area on small-scale fisheries: A fuzzy logic model approach, Fish. Res. 2015; 170: 217-227.

[5] Valderrama, D., and Anderson, J. L. Market interactions between aquaculture and common-property fisheries: Recent evidence from the Bristol Bay sockeye salmon fishery in Alaska. Journ. Env. Econom. Manag. 2010; 59(2): 115-128.

[6] FAO. The State of World Fisheries and Aquaculture. Opportunities and challenges. 2014. Rome.

[7] EC [European Commission] Coastal zones: achieving sustainable management. 2014. Available online in http://ec.europa.eu/environment/integration/research/newsalert/pdf/coastal_zones_sustai nable_management_46si_en.pdf

[8] EU [European Parliament] Report on small-scale coastal fishing, artisanal fishing and the reform of the common fisheries policy (2011/2292(INI)) 2012. Available online in http://www.europarl.europa.eu/sides/getDoc.do?pubRef=-//EP//TEXT+REPORT+A72012-0291+0+DOC+XML+V0//EN

[9] EC[European Commission] Regulation (EU) No 508/2014 of the European Parliament and of the Council of 15 May 2014 on the European Maritime and Fisheries Fund and repealing Council Regulations (EC) No 2328/2003, (EC) No 861/2006, (EC) No 
1198/2006 and (EC) No 791/2007 and Regulation (EU) No 1255/2011 of the European Parliament and of the Council. 2014b. Available in http://eur-lex.europa.eu/legalcontent/DE/TXT/?uri=uriserv:OJ.L_.2014.149.01.0001.01.ENG Accessed 10 june 2015.

[10] Berkes, F. Evolution of co-management: role of knowledge generation, bridging organization and social learning. Journ. Environm. Manag. 2009; 90: 1692-1702.

[11] Hatchard, J.L. and Gray, T.S. From RACs to Advisory Councils: Lessons from North Sea discourse for the 2014 reform of the European Common Fisheries Policy. Mar. Policy 2014; 47: 87-93.

[13] Brewer, T.D. and Moon, K.(2015) Towards a functional typology of small-scale fisheries co-management informed by stakeholder perceptions: A coral reef case study. Mar. Policy 2015; 51: 48-56.

[14] Von Essen, L. M., Ferse, S. C., Glaser, M., and Kunzmann, A. Attitudes and perceptions of villagers toward community-based mariculture in Minahasa, North Sulawesi, Indonesia. Ocean \& Coast. Manag. 2013; 73: 101-112.

[15] Pollnac, R.B., Pomeroy, R.S. and Harkes, I.H.T. Fishery policy and job satisfaction in three Southeast Asian fisheries. Ocean \& Coast. Manag 2001; 44: 531-44.

[16] Christie, P. Marine Protected areas as Biological Successes and Social Failures in Southeast Asia. American Fisheries Society Symposium. 2004. Available online at http://media.eurekalert.org/aaasnewsroom/2004/4Christie-Paper.pdf, Accessed 8 May 2015.

[17] Hollup, O. Structural and sociocultural constraints for user-group participation in fisheries management in Mauritius. Mar. Policy 2000; 24: 407-421.

[18] Cataudella, S., Massa, F. and Crosetti, D. Interaction Between Aquaculture and Capture Fisheries: a methodological perspective 2005, FAO, Rome. 
[19] Jentoft, S. and Chuenpagdee, R. Concerns and Problems in Fisheries and Aquaculture - Exploring Governability. 2013: 33-44 in Bavinck, M., Chuenpagdee, R. Jentoft, S. and Kooiman, J. eds. Governability of Fisheries and Aquaculture (Netherlands, Springer).

[20] Ross, N. Understanding the Fishing 'Community': The Role of Communities of the Mind. Sociol. Rural. 2015; 55: 309-324.

[21] Herrera-Racionero, P., Lizcano-Fernández, E., and Miret-Pastor, L. "Us" and "them". Fishermen from Gandía and the loss of institutional legitimacy. Mar. Policy 2015; 54: 130-36.

[22] Ulfsdatter S. Moral discourse in fisheries co-management: a case study of the Senja fishery, northern Norway. Ocean \& Coast. Manag. 2006; 49: 147-63.

[23] Jentoft, S. Legitimacy and disappointment in fisheries management. Mar. Policy 2000; 24: 14-148.

[24] Etzkowitz, H. Leydesdorff, L. The dynamics of innovation: from National Systems and "Mode 2" to a Triple Helix of university-industry-government relations. Res. polic. 2000; 29(2): 109-123.

[25] MAGRAMA. Plan Estratégico de Innovación y Desarrollo Tecnológico. Pesca y Acuicultura. 2014. Gobierno de España. (Spanish Ministry of Agriculture, Food and Environment). Madrid

[26] Stead, S.M. A comparative analysis of two forms of stakeholder participation in European aquaculture governance: self-regulation and integrated coastal zone management. 2005: 179-192 in Gray, T. S. ed. Participation in fisheries governance (Netherlands, Springer)

[27] Simpson, S. La revolución azul, Revista Investigación y Ciencia 2011; 65: 81-87 
[28] Féral, F. Maritime societies, fisheries law and institutions in the western Mediterranean; A summary of collective rights and decentralized systems of professional discipline. 2004. FAO Fisheries Technical Paper 420 (Rome, FAO), no. 420

[29] Salmi, P. Constraints and Opportunities for Small-Scale Fishing Livelihoods in a Post-Productivist Coastal Setting. Soc. Rur 2015; 55: 258-274.

[30] Bruneel, J., D'Este, P. and Salter, A. Investigating the factors that diminish the barriers to university-industry collaboration. Res. Polic. 2010; 39: 858-868.

[31] Fernández-Ribas, A. Public support to private innovation in multi-level governance systems: An empirical investigation. Scienc. Pub. Pol. 2009; 36 (6): 457-467.

[32] Laranja, M., Uyarra, E., and Flanagan, K. Policies for science, technology and innovation: Translating rationales into regional policies in a multi-level setting. Res. Pol. 2008; 37 (5): 823-835.

[33] Stirling, A. A general framework for analysing diversity in science, technology and society. J. Royal Soc. Interf. 2007; 4(15): 707-719.

[34] Stirling, A. Opening up" and "closing down" power, participation, and pluralism in the social appraisal of technology. Scienc., Technol. \& Hum. Val. 2008; 33(2): 262-294. [35] Van Dijk, T. Principles of Critical Discourse Analysis. Disc. \& Societ. 1993; 4: 249283.

[36] Fairclough, N. (2013) Critical Discourse Analysis: The Critical Study of Language 2013. Routledge. New York.

[37] Wynne, B. Misunderstood Misunderstanding: social identities and public uptake of science. Pub. Underst. of Scienc. 1992; 1 (3): 281-304.

[38] Woolgar, S. Science: the Very Idea. 1988. Routledge. London 
[39] Hardin, G. The tragedy of the commons. Scienc.1968; 162: 1243-8.

[40] Callon, M., Lascoumes, P. and Barthe, Y. (2009).Acting in an uncertain world: An essay on technical democracy. 2009. MIT Press. Cambridge.

[41] Stange, K., van Tatenhove, J. and van Leeuwen, J. Stakeholder-led knowledge production: Development of a long-term management plan for North Sea Nephrops fisheries. Scienc. and Pub. Pol. 2015; 42: 501-513. 